\title{
Dual Energy X-Ray Absorptiometry in Morphological Asymmetry Assessment among Field Hockey Players
}

\author{
by \\ Magdalena Krzykała ${ }^{1}$
}

\begin{abstract}
Every sports discipline is characterized by specific movements which are symmetric or asymmetric. Field hockey belongs to a asymmetric activity. There is suspicion that players, who use more frequently one side of the body during training or the game, have also side-to-side morphological diversification. The main aim of the study is to determine the degree of asymmetry which manifests itself in somatic characteristics. The analysis was done among twenty competitive Polish male field hockey players. All athletes undertook total body Dual X-Ray Absorptiometry (DXA) scans, which divided the body into anatomic segments: arms, trunk, and legs. Professional field hockey participation showed significantly enhanced muscle mass and higher bone mineral density on the left side of the body. The present data should help better understand complicated morphology of highly trained athletes with more comprehensive and accurate approach to their anthropometrical description.
\end{abstract}

Key words: side-to-side morphological diversification, sport, body components.

\section{Introduction}

It is well known that physical exercises play very important roles in gaining body mass and increasing bone mineral density. It was shown that bones with higher density are stronger, so small reductions in bone density may be associated with large reductions in bone strength, which could be connected with developing stress fracture (Alho et al., 1986). Additionally, as stated by some authors (Bennell et al., 1999), stress fractures could also be a result of body size and composition, including total and regional lean and fat mass. Bone tissue causes changes in mass and strength. This process is connected with physical loading and frequency of loading which is applied (Chilibecks et al., 1995). Wolman (1990) has shown that exercise produces a local effect on the skeleton (at the site of maximum stress). The differences in physical activity could, thereby, affect anthropometric asymmetry (Shell et al., 1985).
Morphological asymmetry - the difference between the right and left sides of the body is not well understood, yet. Asymmetry in body dimensions are often rather the norm than the exception for humans. On the other hand, it is unlikely that organisms will attain perfect symmetry in all traits. As stated by some authors (Al-Eisa et al., 2004), the amount of asymmetry that can be tolerated in a bilateral trait would relate to the functionality of the trait. Bussey (2010) suggested that there is a link between asymmetric lower body movement patterns in some sport disciplines, such as field hockey and pelvic asymmetry. It could be connected with adaptation to the asymmetrical loading demands of the sport in order to decrease strain in some tissues. Also, lower limb asymmetry was connected with LBP (low back pain) by some authors (Al-Eisa et al., 2004).

Some deviations from perfect symmetry in humans in morphologically bilateral traits are referred to as fluctuating asymmetry. Many anthropometric characteristics show a consistent side bias. Level of

\footnotetext{
${ }^{I}$ - University School of Physical Education, Poznan, Poland, Department of Anthropology and Biometry
} 
asymmetry in not constant. As was stated by Manning et al. (2002), asymmetries are in the order of $1 \%$ of some trait's total size, so small percentage changes in left and/or right traits may result in large percentage changes in asymmetries.

Some studies stated that morphological asymmetry tend to be greater in upper than in lower limbs, and show a right side bias in the upper limbs (Munter, 1936; Tomkinson et al., 2003; Ulijaszek and Mascie-Taylor, 2005). In sport there is a need to seek certain solutions to achieve the highest results. It is quite important with elite athletes. Those solutions are concentrated among training methods modification or biological regeneration. Also, having a certain level of morphological parameters is very important and differs in accordance to the sport discipline or position on the field. Many researches proved that morphological asymmetry exist in sport (Dorado et al., 2002; Auerbach and Ruff, 2006; Starosta, 1990). Moreover, it was stated that asymmetry is negatively correlated with physical performance (Manning and Pickupk, 1998) and body size (Manning, 1995) in males. Observation of the scale of this phenomenon is very important in case its elimination is necessary. It could have different values and it is stated that when it access some level, it may hinder some special activity practice, could negatively affect the health (being connected with functional asymmetry and some changes for example in the area of spine) and impede optimal sport performance. So deep asymmetry could have multiple consequences. In this case it is very important to take action and compensate for this pathology.

There are different methods which could be used to analyze side-to-side morphological differences. One such method is dual energy $x$-ray absorptiometry (DXA). Each method has its own advantages and disadvantages. As stated by some authors (Calbet et al., 1998), this method gives a general idea about the specific sport loading influence on bone mineral content (BMC). On the other hand, it is not possible to assess the effect of sport participation to individual bones during DXA analysis, because this exam involves all bone structures simultaneously. There are also some concerns about measurement biases related to the impact of a significant change in lean tissue hydration. Some studies, however, showed no significant alterations in the estimates for bone, lean and fat mass (Pietrobelli et al., 1998). Despite all of the mentioned limitations, DXA is a widely used method, owing to its ease of use, availability, low- radiation exposure, good accuracy and reproducibility for the assessment of regional body composition. It was, thereby, our rationale for its use in the present study. There is limited data about morphological asymmetry in men's field hockey, which is an internationally popular sport. Therefore, the aims of this study were to determine if values for analyzing morphological parameters differ significantly between sides, and then assess the degree of right and left body morphological asymmetry among Polish elite male field hockey players.

\section{Materials and methods}

Twenty competitive male field hockey players were included in this study. The mean age of athletes was $24,4(\mathrm{SD}=4,93$ years). The range of age was 18-34 years. All athletes had played organized competitive hockey at a senior (national) Polish level. Average training years of all competitors was $17 \mathrm{y}$ and ranged between $13 \mathrm{y}$ and $24 \mathrm{y}$. The research was obtained in December 2008 y, during the competitive period for indoor hockey. All athletes were questioned to determine hand preference during manual activities. It was established that all analyzed field hockey players were right-handed.

Ethical approval was provided by a local medical university ethics committee and individual consent was provided.

Body measurements were taken using standardized procedures (Martin, 1928). Stature was measured to the nearest $0.1 \mathrm{~cm}$ with a stadiometer. Weight was measured to the nearest $0.1 \mathrm{~kg}$ with a beam-balance scale.

Total body DXA scans were done using LUNAR PRODIGY ADVANCE (GE, Madison, WI, USA) densitometer with enCORE software (GE Helthcare v.10.50.086) among all field hockey players involved in this study. Body composition analysis, including fat tissue $(\mathrm{g})$, percent fat, lean tissue $(\mathrm{g})$, total mass $(\mathrm{kg})$ and bone mineral density $(\mathrm{BMD})(\mathrm{g} / \mathrm{cm} 2)$ was determined for right and left sides of the body. All subjects were measured while wearing standard light shirts to minimize clothing absorption, with all metallic objects removed before assessment. Measurements were performed by a trained radiology technician. Total body scanning area was divided into anatomic segments: arms, trunk and legs.

For all researched parameters, subjects' homogeneity with normal distribution was checked. The Shapiro-Wilk test was used to check homogeneity estimation. Statistical values of $p \leq 0.05$ were consid- 
Table 1 Anthropometric characteristic of athletes

\begin{tabular}{lc}
\hline Parameters & $\bar{x} \pm$ SD \\
\hline Anthropometry & $77.53 \pm 9.34$ \\
Weight, kg & $178.22 \pm 6.40$ \\
Height, cm & $24.41 \pm 4.93$ \\
Age, yr & \\
DXA & \\
Whole body lean, g & $61651.50 \pm 5457.04$ \\
Whole body fat, g & $12897.35 \pm 6533.50$ \\
$\%$ body fat & $16.7 \pm 7.02$ \\
BMD, g/cm 2 & $1.33 \pm 0.073$ \\
\hline
\end{tabular}

ered significant. For BMD, lean and fat tissue, values of mean $(\bar{x})$ and standard deviation (SD) were calculated. The significant differences in mean body values between right and left body segments for variables with normal distribution were checked with Students t-test. The significant differences in mean body values between right and left body segments for variables with distribution variances from normal were checked with the Wilcoxon test. All statistical procedures were carried out using Statistica 8.0 software.

\section{Results}

The mean body height of field hockey players was $178.22 \pm 6.40 \mathrm{~cm}$ and body weight was $77.53 \pm$ $9.34 \mathrm{~kg}$ (Table 1). The anthropometric characteristics on both sides of the body, done by dual energy x-ray absorptiometry, are described in Table 2. There are significant differences in body mass density of the right and left legs $(1.576 \pm 0.0909 \mathrm{~g} / \mathrm{cm} 2$ vs. $1.611 \pm$ $0.1062 \mathrm{~g} / \mathrm{cm} 2$, respectively (to use "respectively', the reader must know what it's in reference to. You must denote which value is the right and which is the left leg): $p=0.0086$ ) and of the right and left trunk $(1.111 \pm 0.0609 \mathrm{~g} / \mathrm{cm} 2$ vs. $1.137 \pm 0.0729 \mathrm{~g} / \mathrm{cm} 2$, respectively: $p=0.0008)$. In turn, there were no differences between right arm $(1.017 \mathrm{~g} / \mathrm{cm} 2)$ and left arm $(1.014 \mathrm{~g} / \mathrm{cm} 2)$, as well as between total bone mineral density on the right and left sides of the body $(1.326 \pm 0.0741 \mathrm{~g} / \mathrm{cm} 2$ vs. $1.338 \pm 0.0754 \mathrm{~g} / \mathrm{cm} 2$, respectively: $p=0.1310)$. The larger values in body density were in the left legs, left trunk and total body of athletes. The individual differences between the left and right sides of a particularly body segment were shown in Figure 1. The biggest diversity between left and right sides were seen in the legs. Other body segments proved to have much smaller, if not very similar, levels between the opposing sides.

Significant differences in side-to-side lean tissue morphology were observed in every measured parameter. The lean tissue of the arms, legs, trunk and total body were higher on the left side of the body. The lean tissue of the right and left arm was $3738 \pm$ $454.9 \mathrm{~g}$ and. $4046 \pm 420.7 \mathrm{~g}$, respectively $(\mathrm{p}=0.0000)$, whereas lean tissue of the right and left leg was $10578 \pm 1050.9 \mathrm{~g}$ and. $10904 \pm 1054.5 \mathrm{~g}$, respectively $(\mathrm{p}=0.0000)$. Lean tissue was also larger in the left side of trunk in comparison to the right $(14371 \pm 1580.6 \mathrm{~g}$ and $13996 \pm 1436.7 \mathrm{~g}$, respectively). Significant differences were observed for total right and left lean tissue $(30444 \pm 2759.5 \mathrm{~g}$ and $31208 \pm 2814.5 \mathrm{~g}$, respectively: $\mathrm{p}=0.0073$ ).

Figure 2 shows the diversification among all athletes in lean tissue morphology of every analyzed part of the body. There is clear similarity in arms and legs among field hockey players, as opposed to the trunk and total lean body tissue.

Similar findings were observed with body fat analysis. Across all body segments, the amount of morphological asymmetry was significantly greater in the left side of the body. Individual analysis (Figure 3) shows significant diversity in fat mass, mainly in the trunk and total body.

Table 2

Morphological parameter comparisons between right and left body segments using DXA analysis

\begin{tabular}{llccc} 
& & BMD $\left(\mathbf{g} / \mathbf{c m}^{2}\right)$ & $\overline{\text { FAT }} \mathbf{( g )}$ & LBM (g) \\
& & $\bar{x} \pm \mathrm{SD}$ & $\bar{x} \pm \mathrm{SD}$ & $\bar{x} \pm \mathrm{SD}$ \\
\hline \multirow{2}{*}{ ARM } & right & $1.017 \pm 0.0674$ & $522.30 \pm 290.562$ & $3738 \pm 454.9$ \\
& left & $1.014 \pm 0.0642$ & $569.20 \pm 3149.761$ & $4046 \pm 420.7$ \\
\hline \multirow{2}{*}{ LEG } & right & $1.576 \pm 0.0909$ & $2021.45 \pm 945.400$ & $10578 \pm 1050.9$ \\
& left & $1.611 \pm 0.1062$ & $2077.45 \pm 961.829$ & $10904 \pm 1054.5$ \\
\hline \multirow{2}{*}{ TRUNK } & right & $1.111 \pm 0.0609$ & $3581.25 \pm 2020.187$ & $13996 \pm 1436.7$ \\
& left & $1.137 \pm 0.0729$ & $3658.10 \pm 1988.681$ & $14371 \pm 1580.6$ \\
\hline \multirow{2}{*}{ TOTAL } & right & $1.326 \pm 0.0741$ & $6321.75 \pm 3314.446$ & $30444 \pm 2759.5$ \\
& left & $1.338 \pm 0.0754$ & $6525.70 \pm 3277.620$ & $31208 \pm 2814.5$ \\
\hline
\end{tabular}




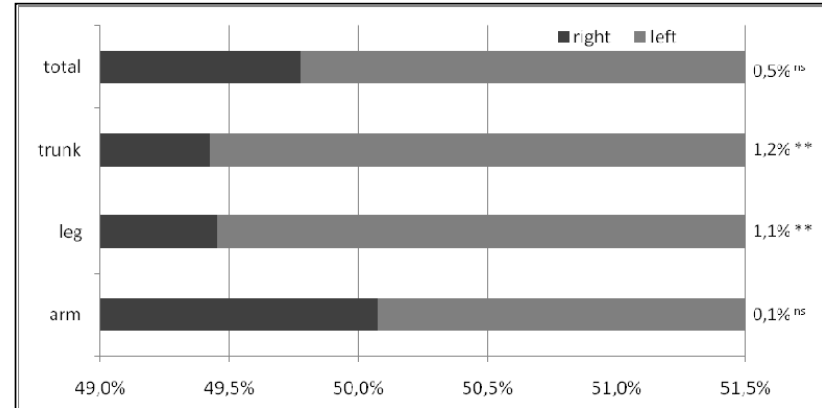

Figure 1

Assymmetrical percentage differences in side-to-side $B M D\left(\mathrm{~g} / \mathrm{cm}^{2}\right)$ morphology between analyzed body segments

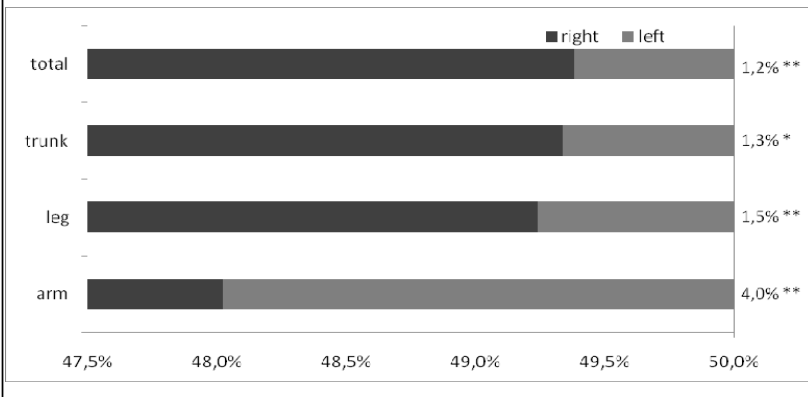

\section{Figure 2}

Asymmetrical percentage differences in side-to-side LEAN (g) morphology between analyzed body segments

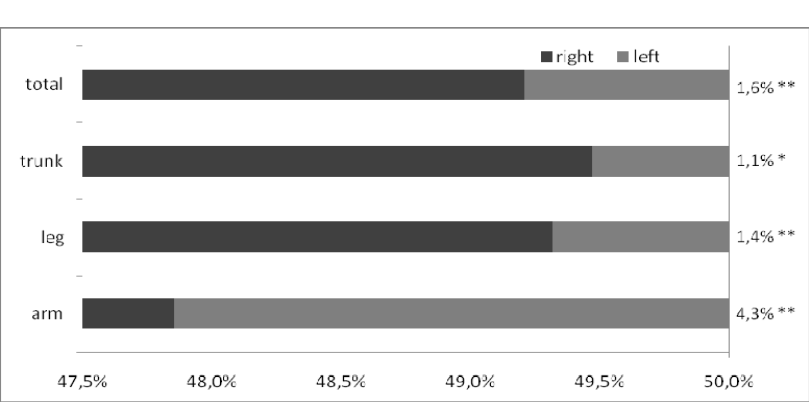

Figure 2

Asymmetrical percentage differences in side-to-side FAT (g) morphology between analyzed body segments $* p \leq 0.05, * * \leq 0.01, n s-$ not significant

\section{Discussion}

The overload principle suggests that there is a possibility to see physical changes in biological tissue when stress is imposed that is greater than tasks of everyday living (Bussey, 2010). The important question is what scale of asymmetry is acceptable for athletes and non-athletes in morphological traits? In young non-active subjects, the dominant arms have $1-2 \%$ greater BMC than the contrateral arm, while typical inter-arm muscle mass differences are $4-5 \%$ (Calbet et al, 2001). According to Palmer (1994), the differences between both sides of a bilateral trait are often very small, usually around $1 \%$ of mean trait size. But the level of asymmetry is dependent on size of the trait, because the same value of asymmetry for smaller and larger dimensions will delineate the difference (Auerbach and Ruff, 2006). Participation in sport activity, especially over the long term, will broadened this difference. It is particularly common in one-sided dominate sports (Ducher et al., 2005). Grace et al. (1984) showed that asymmetry exists if there is greater than $10 \%$ difference for a specific quality between limbs (e.g., muscle girth). This influences the overall laterality of the athlete, which is the preference of one side of the body over the other during specific tasks. It is stated that the lifelong preference for one extremity (e.g., the left arm or the left leg), as well as a predilection for a certain direction when turning around or rotating about one's longitudinal axis, could lead to asymmetry which are seen in morphological characteristics, and which can even influence the bone matrix in competitive athletes. The present study shows that differences between both sides of the body in morphological parameters were significant in most cases among field hockey players. It could be a result of specific, asymmetrical training in this discipline. Leg and trunk bone mineral density were significantly asymmetric, in favor of the left side. Exceptions were with arm and total bone mineral density, which were not significantly asymmetric. By contrast, Nevill et al. (2003) detected no differences in leg BMD between right and left extremities in athletes of 10 various sport disciplines, and significantly greater BMD of the dominant compared with non-dominant arm, only with racket players. Field hockey players in the present study revealed some muscle hypertrophy in the left compared with the right side of the body among arms $(4,7 \%)$, legs $(0,8 \%)$, trunk $(2,5 \%)$ and total body $(2,3 \%)$. Some authors (Calbet et al., 2001; Dorado et al., 2002) also observed similar findings, but with golfers, muscle hypertrophy was observed in the dominant compared with nondominant arm. Greater hypertrophy in the musculature of the dominant side in athletes was also seen by Malina and Buschang (2004). Roi and Bianchedi (2008) observed greater cross-sectional area of the dominant forearm, arm, thigh and calf among international level Italian fencers. Krahl et al. showed (1994) significant differences in bone density of the dominant arm in tennis players, which was due to increased mechanical stimulation on the implement 
limb through its respected usage. Maughan et al. (1986) observed that the dominant arm of tennis players had greater proportion of muscle and smaller proportion of fat than their non- dominant limb. A significant side-to-side difference was also observed in every measured site among tennis and squash Finnish national-level players (Kannus et al., 1995). As stated by Lucki and Nicolay (2007), male tennis players had dominant forearm circumferences of approximately $7.4 \%$ greater than the opposite limb. Jones et al., (1977) examined site-specific accretion of bone in professional tennis players, with differences being up to $30 \%$ between extremities. Similar finding were later done on baseball players (Komi, 1996; Bubanj and Obradovic, 2002). Numerous studies confirmed increased bone density in the dominant limb among tennis players (Ruff et al., 1994; Ducher et al., 2005; Lucki and Nicolay, 2007).

The right-left differences in morphological parameters were observed in athletes engaged in many different asymmetric movement sports. Krawczyk et al. (1998) reported the most pronounced asymmetry in tennis players in forearm, arm girth and elbow width, but he also observed significant asymmetry among kayakers, canoeists, rowers and skaters. Krawczyk concluded that the side-to-side differences in anthropometric measurements of athletes engaged in symmetric movements were lower than in athletes representing one-sided dominated sports. One limb performance during certain activities results in higher limb fitness levels than the opposing limb. Thus, the training limb becomes the dominate limb, in spite of athlete's predisposition to right handedness, left handedness or ambidextratity (Starosta, 1990). According to some authors (Chilibeck et al., 2000), bone mineral density is higher in dominant vs. nondominant arms because of greater use of the dominant arm in everyday activities, which influences osteoblastic bone activity. It was additionally postulated that genetic predispositions towards enhanced BMD are predetermining elements of segmental girth. Increased BMD in the dominant arm was also observed in our study, but the difference was small and not statistically important. When one considers that carrying loads with the preferred hand means a stress on the arm muscles of the same side and a simultaneous activation of the contra-lateral muscles for the stabilization of one's balance, these functional asymmetries become plausible. It is also remarkable that hurdlers, high jumpers and pole vaulters exhibit higher muscle contractility in their swing-leg than in their take-off leg (Absauomov, 1976) because of the higher mechanical load.

It is obvious that morphological side-to-side diversification depends on sport specificity. Field Hockey is a one-sided dominant sport. This implies that athletes have a preference of one side of the body over the other. There are many different specific movements in this discipline. Many of such movements involve rapid rotation of the hips, shoulders and arms, such as the push-in movement (Kerr and Ness, 2006). This movement stats with the body counter-rotated where the right side of the body is behind the left side (with respect to the direction of ball trajectory). Kerr and Ness (2006) found that pelvic and shoulder girdle maximum angular velocities occurred concurrently from left arm to the right arm. Similar findings were described by Mc Laughlin (1997). Many published studies focused on many components of field hockey, such as the hit (Burges-Limerick et al., 1991), the push (Alexander, 1983), the slap shot (Cresswell and Elliott, 1987), and the push-in and trap phases of the penalty corner (Kerr and Ness, 2006), describing specificity of characteristic movements, which could appeared in an athlete's morphology.

It is stated that body composition of athletes should be considered with reference to regional BMD, FFM and FM distribution (Bell et al., 2005). Such information could be important in better understanding both their morphological characteristics and talent development, or sports performance. Additionally, Manning and Pickup (1998) stated that the national league athletes would be more symmetric, because symmetry is positively related with physical performance in adult males. On the other hand, marked structural asymmetry is usually associated with more intensive unilateral activity in some sport disciplines (Kannus et al., 1995; Roi and Bianchedi, 2008; Lucki, 2007), especially in highly skilled players with a long history competition, (Tsolakis et al., 2006). Tsolakis reported significant variances between arm asymmetries and years of training. Further longitudinal research in this area could provide deeper insight into specific responses on specific training that require asymmetrical limb use, and evaluating morphological asymmetry of athletes. It could be important to individualized symetrization process among the athletes, because they do not have the same level of morphological differences. It is obvious that this process should be done methodologically (Starosta, 1990). After the few 
first stages, movements symetrization could be used during training and the competitions, which could give quite big advantage over the opponents during the game. Regular exercises focused on body symmetry development could be effective for athletes in improving sport performance. This could be a valid argument for coaches to place emphasis on research oriented to morphological asymmetry among players.

This study confirmed existing differences in right and left sides of the body in most of the researched parameters among elite athletes. It is seems that there is a need to encourage researchers to further seek correlations between morphological asymmetry and many external factors, such as training years of athletes. The number of training years of a particularly athlete. Individual analysis is also important because some athletes could be more prone to short- or long-term changes in asymmetry than others. Because of the relatively small sample size, the results of the present study must be approached cautiously and future research should significantly expand the sample size.

\section{Conclusions}

1. The effectiveness of every part of the body (especially those where asymmetry was observed) may be improved by development of muscle mass (lean) on the right side of the body to decrease morphological asymmetry.

2. Morphological asymmetry could have some consequences in sport results and could lead to disadvantageous functional changes in the body (for example, in the area of the spine). Hence, it is very important to lead symetrization process in training and regularly monitor the degree of asymmetry in different parts of the human body, as to maximize athletic performance and potentially minimize injury.

\section{References}

Absauomov TM. et al. Kontraktionsgeschwin-digkeit von Muskeln und ihre Veranderung im sportlichen Training, in Leistungssport, 1976. 1: 58-61.

Al-Eisa E, Egan D, Wassersug R. Fluctuating asymmetry and low back pain. Evol Hum Behav, 2004. 25 : $31-37$.

Alexander M. The footwork pattern in the push stroke. Counterattack, 1983. 3 (1): 14-18

Alho A, Husby T, Hoiseth A. Bone mineral content and mechanical strength: an ex vivo study on human femora at autopsy. Clin Orthop Relat Res, 1986. 227: 292-297.

Auerbach BM, Ruff CB. Limb bone bilateral asymmetry: variability and commonality among modern humans. J Hum Evol, 2006. 50: 203-218.

Bell W, Evans WD, Cobner DM et al. The regional placement of bone mineral mass, fat mass, and lean soft tissue mass in young adult Rugby Union players. Ergonomics, 2005. 48 (11-14): 1462-1472.

Bennell K, Matheson G, Meeuwisse W et al. Risk Factors for Stress Fracture. Sports Med, 1999. 28 (2): $91-122$.

Bubanj S, Obradovic B. Mechanical Force and Bones Density, Facta Universitatis. Series: Physical Education and Sport, 2002. 1(9): 37-50.

Burgess-Limerick R, Abernethy B, Neal RJ. Experience and back swing movement time variability: a short note concerning a serendipitous observation. Hum Mov Sci, 1991. 10: 621-627.

Bussey MD. Does the demand for asymmetric functional lower body postures in lateral sports related to structural asymmetry of the pelvis. J Sci Med in Sport, 2010. 13: 360-364.

Calbet JAL, Dorado C, Diaz-Herrera P et al. High femoral bone mineral content and density in male football (soccer) players. Med Sci Sports Exerc 2001. 33 (1) : 682-1687.

Chilibeck PD, Sale DG, Webber CE. Exercise and bone mineral density. Sports Med, 1995. 19: 103-122.

Chilibeck PD, Davison KS, Sale DG et al. Effect of physical activity on bone mineral density assessed by limb dominance across the lifespan. Am J Hum Biol, 2000. 12 (5): 633-637.

Cresswell A, Elliott B. The slap shot or drive in field hockey: a dilemma. Sport Coach, 1987. 9: 21-23. 
Dorado C, Sanches Moysi J, Vicente G et al. Bone mass, bone mineral density and muscle mass in professional golfers. J Sports Sci, 2002. 20: 591-597.

Ducher G, Courteix D, Arlettaz A et al. Effects of long-term tennis playing on the muscle-bone relationship in the dominant and nondominant forearms. Can J Appl Physiol, 2005. 30: 3-17.

Ducher G, Courteix D, Meme S. et al. Bone geometry in response to long-term tennis playing and its relationship with muscle volume: a quantitative magnetic resonance imaging study in tennis players. Bone, 2005.37 (4): 457-466.

Jones H, Priest J, Hayes W, Tichenor C et al. Humeral hypertrophy in response to exercise. J Bone Joint Surg, 1977. 59a: 204-208.

Kannus P, Haapasalo H, Sankelo M, Sievanen H, Pasanen M, Heinonen A, Oja P, Vuori I. Effect of starting age of physical activity on bone mass in the dominant arm of tennis and squash players. Ann of Internal Med, 1995. 123: $27-31$.

Kerr R, Ness K. Kinematics of the Field Hockey Penalty Corner Push-in. Sports Biomech, 2006.5 (1): $47-61$.

Komi PV. Strength and Power in Sport, in: volume III of The Encyclopaedia of Sports Medicine (284-88). Blackwell science, 1996.

Kannus P, Haapasalo H, Sankelo M, Sievanen H, Pasanen M, Heinonen A, Oja P, Vuori I. Effect of starting age of physical activity on bone mass in the dominant arm of tennis and squash players. Ann Intern Med, 1995, 123 (1): 27-31.

Krahl H, Michaelis U, Pieper H et al. Stimulation of bone growth through sports. A radiologic investigation of the upper extremities in professional tennis players. Am J Sport Med, 1994. 22 (6): 751-757.

Krawczyk B, Skład M, Majle B. et al. Lateral asymmetry in upper and lower limb measurements in selected groups of male athletes. Biol Sport, 1998. 15 (1): 33-38.

Lucki NC, Nicolay CW. Phenotypic Plasticity and Functional Asymmetry in Response to Grip Forces Exerted by Intercollegiate Tennis Players. Am J Hum Biol, 2007. 19: 566- 577.

Malina RM, Bouchard C, Bar-Or O. Growth, Maturation and Physical Activity. Hum Kinetics, 2004.

Manning JT, Pickup LJ. Symmetry and performance in middle distance runners. Int J Sports Med, 1998. 19: 205209.

Manning JT. Fluctuating asymmetry and body weight in men and women: implications for sexual selection. Ethol Sociobiol, 1995. 16: 145-153.

Manning JT, Gage AR, Diver MJ et al. Short-term changes in asymmetry and hormones in men. Evol Hum Behav, 2002. 23: 95-102.

Martin R: Lehrbuch der Anthropologie. Jena. 1928.

Maughan RJ, Abel RW, Watson JS. et al. Forearm Composition and Muscle Function in Trained and Untrained Limbs. Clin Physiol, 1986. 6: 389-396.

McLaughlin P. Three-dimensional biomechanical analysis of the hockey drag flick. Full report to the Australian Sports Commission. Belconnen: Australian Sports Commision, 1997.

Munter AH. A study of the lengths of the long bones of the arms and legs in man, with special reference to AngloSaxon skeletons. Biometrika 1936. 28: 258-294.

Nevill AM, Holder RL, Steward AD. Modeling elite male athlete's peripheral bone mass, assessed using regional dual x-ray absorptiometry. Bone, 2003. 32: 62-68.

Palmer AR. Fluctuating asymmetry analyses: a primer. In Developmental Instability: Its Origins and Evolutionary Implications (ed by TA Markow), pp.355-364. Dordrecht: Kluwer Academic. 
Pietrobelli A, Wang Z, Formica C eta al. Dual-energy X-ray absorptiometry: fat estimation errors due to variation in soft tissue hydration. Am J Physiol, 1988, 274: 808-816.

Roi GS, Bianchedi D. The Science of Fencing. Implications for Performance and Injury Prevention. Sports Med, 2008. 38 (6): 465-481.

Ruff CB, Walker A, Trinkaus E. Postcranial robusticity in Homo. III Ontogeny. Am J Phys Anthropol, 1994. 93:3554.

Starosta W. Symmetry and asymmetry of movements in sport. Institutute of Sport, Warsaw, Poland, 1990.

Tomkinson GR, Popovic N, Martin M. Bilateral symmetry and the competitive standard attained in elite and subelite sport. J Sports Sci, 2003. 21: 201-211.

Tsolakis $\mathrm{CH}$, Katsikas $\mathrm{CH}$. Long term effects of a combined physical conditioning and fencing training program on neuromuscular performance in elite fencers, Int J Fitness, 2006.2 (1): 35-42.

Ulijaszek SJ, Mascie-Taylor CGN. Anthropometry: the individual and the population, Chapter 2, 2nd, New York. Cambridge University Press, 2005.

Wolman RL. Bone mineral density levels in elite female athletes. Ann Rheum Dis, 1990.49 (12): 1013-1016.

\section{Acknowlegdement}

This study was founded by University School of Physical Education in Poznań.

I would like to thank the players and the team coach for permission to test his athletes during the competitive period.

\section{Corresponding author}

\section{Magdalena Krzykała}

Department of Anthropology and Biometry

University School of Physical Education, Poznań, Poland

phone: +48 618355230

fax: +48 618355126

e-mail: krzykala@awf.poznan.pl 